\title{
What evidence exists for the impact of Baltic Sea ecosystems on human health and well-being? A systematic map protocol
}

\author{
Joanna Storie ${ }^{1}$, Monika Suškevičs', Mart Külvik', Virpi Lehtoranta² ${ }^{2}$ Suvi Vikström², Simo Riikonen², Harri Kuosa²,
} Kristin Kuhn ${ }^{3}$ and Soile Oinonen ${ }^{2^{*}}$

\begin{abstract}
Background: The Baltic Sea ecosystems supply many benefits to society, termed ecosystem services. These depend upon a healthy marine environment requiring marine and relevant land-based policies integrated with public health policies. Until recently marine environment protection policies have largely focussed on human impacts on the environment and have not taken into account impacts of ecosystems on human health beyond the direct impacts of hazardous substances, such as those present in seafood. Whilst endeavours have been made to integrate human health and well-being into marine policies, interviews with key stakeholders through a participatory process revealed that the linkages were not sufficiently strong to inform policymaking. The existing evidence base urgently needs to be identified and synthesised to support relevant policy updates of the Marine Strategy Framework Directive (MSFD) 2008/56/EC and the Baltic Sea Action Plan (BSAP) (2007) as well as to help direct future research priorities.

Method: The protocol is based on the primary question, "What linkages have been researched between Baltic Sea ecosystems and the positive and negative impacts to human health and well-being?" Using systematic mapping, this study will identify and map the state and the geographical distribution of the existing research evidence linking human health and well-being with the Baltic Sea ecosystems. The types of ecosystem services supplied by the Baltic Sea and the associated health and well-being impacts will be categorised and presented in a graphical matrix, illustrating ecosystem service type and the types of health and well-being outcomes. The systematic mapping procedure will result in a narrative report published with a searchable database, which will contain a descriptive summary of the information from all of the eligible studies. The systematic map and database will be displayed on the website of the Finnish Environment Institute (SYKE).
\end{abstract}

Keywords: Evidence synthesis, Participatory approach, Systematic map, Policy relevance, HELCOM region, Ecosystem services, Marine and coastal

\section{Background}

Recently there has been an upsurge of interest in the impacts on human health and well-being and the role played by the marine environment $[1,12,21]$. Health and well-being definitions can range from the functional

\footnotetext{
${ }^{*}$ Correspondence: soile.m.oinonen@ymparisto.fi

2 Finnish Environment Institute, Latokartanonkaari 11, 00790 Helsinki, Finland

Full list of author information is available at the end of the article
}

approach where life expectancy is considered a proxy to a more holistic understanding that includes multiple factors. We will reflect the broadest interpretation of health and well-being possible using McKinnon et al's domains and definitions (see Table 1).

There is a call for greater clarity in describing how the marine environment impacts health and well-being [25]. The BONUS-ROSEMARIE project: "Blue health and wealth from the Baltic Sea-a participatory systematic 
Table 1 Domains and definitions of human well-being outcomes [28]

\begin{tabular}{|c|c|}
\hline Domain & Code definition \\
\hline Economic living standards & Income, employment, employment opportunities, wealth, poverty, savings, payments, loans \\
\hline Material living standards & $\begin{array}{l}\text { Assets owned, access and availability of food, fibre and fuel basic infrastructure (electricity, water, telecommunica- } \\
\text { tions and transportation), shelter }\end{array}$ \\
\hline Health & $\begin{array}{l}\text { Physical health, nutrition, longevity/life expectancy, maternal health, child health, access to health care, occurrence } \\
\text { of diseases, mental health }\end{array}$ \\
\hline Education & $\begin{array}{l}\text { Education infrastructure (access to school, access to training, quality of education); informal education (transfer } \\
\text { of knowledge and skills includes livelihood skills, traditional knowledge and skills); formal education (degrees } \\
\text { awarded, students enrolled) }\end{array}$ \\
\hline Social relations & $\begin{array}{l}\text { Interactions between individuals, within and/or between groups (communities, stakeholders, ethnic groups, gen- } \\
\text { der); conflict, relationships, connectedness, ability to work together, ability to help others, and trust }\end{array}$ \\
\hline Security and safety & $\begin{array}{l}\text { Physical security (personal safety and security), resource security; tenure security; human rights; vulnerability, } \\
\text { resilience and adaptive capacity }\end{array}$ \\
\hline Governance (and empowerment) & $\begin{array}{l}\text { Structures and processes for decision making including both formal and informal rules; includes participation and } \\
\text { control in decision making, accountability, justice, transparency and governance skills }\end{array}$ \\
\hline Subjective well-being & Measures of happiness, quality of life, satisfactions supported by some value of ecosystem(s) and/or resources \\
\hline Culture and spirituality & $\begin{array}{l}\text { Cultural, societal and traditional values of natural resources and nature to the community; sense of home; cultural } \\
\text { identity and heritage; spiritual or religious beliefs and/or values }\end{array}$ \\
\hline Freedom of choice and action & Ability to pursue what you value doing and being \\
\hline
\end{tabular}

review for smart decisions" arose from a call from the BONUS secretariat (the legal management organisation of BONUS-joint Baltic Sea research and development programme) [6] to address these challenges. This synthesis focuses on the existing knowledge of the Baltic Sea ecosystems impacts on human health and wellbeing and seeks to make this an accessible resource for policymakers.

Health and well-being is a multidimensional concept that goes beyond a lack of disease and infirmity. It includes access to various supportive resources and networks to enable individuals to function well in society [35]. While investigations are ongoing to investigate health and well-being in European oceans generally, none are specifically focussed on the unique environment of the Baltic Sea nor to connect them to ecosystem services.

A limited number of review articles have explicitly connected ecosystem services to human health and wellbeing [26, 35, 36]. Martin et al. [26], for example, cover a wide geographical scope but restricted to marine and coastal cultural ecosystem services topics. Summers et al. [36] propose elaborating different well-being categories, such as basic needs, economic needs, environmental needs and subjective well-being and their interactions with ecosystem services. It is one of the few review papers which has tried to disentangle the multidimensional nature of the well-being concept and its relationship to ecosystem services [26, 35].

Based on a comprehensive (non-systematic) literature assessment, Sandifer et al. [35] explore the links between nature, biodiversity, ecosystem services and human health as well as other well-being parameters. They conclude that since the health benefits from the ecosystem services are only just beginning to be appreciated, the evidence in the literature is limited; therefore, more in-depth research is needed to explore these linkages, including coastal and marine ecosystem services.

Globally, further systematic reviews on the topic have been conducted recently. Blythe et al. [5] present a systematic review and synthesis of 50 articles between 2008 and 2018 on coastal well-being and ecosystem services. One of their conclusions is that there is a degree of uncertainty about well-being outcomes and that "there is limited empirical evidence linking particular management institutions to different bundles of ecosystem services and well-being" (p. 8). Ban et al. [3], based on a systematic review and synthesis of 118 articles of marine protected areas (MPAs), found that positive and negative well-being outcomes were divided half-half, and most studies focused on economic and governance aspects, while social, cultural and health domains were understudied (p. 524). A similar review studying the Marine Protected Areas (MPA) well-being links by Rasheed [33] $(n=63$ articles) concludes that only a few aspects of wellbeing are studied, and calls for a more systematic and integrative framework to capture these aspects.

The Baltic Sea supplies a unique ecosystem as the largest brackish water environment for a total of almost 149 million people from the European Union countries (see Table 2). Flows from the North Sea are low and therefore it depends on freshwater inflows for oxygenation. Biodiversity within is low but highly fragile. The Baltic Sea is governed under the Baltic Sea Action Plan by HELCOM (Baltic Marine Environment Protection 
Table 2 Populations of EU countries bordering the Baltic Sea

\begin{tabular}{lr}
\hline $\begin{array}{l}\text { Eurostat data: populations of EU countries surrounding the Baltic } \\
\text { Sea 1st Jan 2019 [11] }\end{array}$ \\
\hline Denmark & $5,806,081$ \\
Germany & $83,019,214$ \\
Estonia & $1,324,820$ \\
Latvia & $1,919,968$ \\
Lithuania & $2,794,184$ \\
Poland & $37,972,812$ \\
Finland & $5,517,919$ \\
Sweden & $10,230,185$ \\
Total & $148,585,183$
\end{tabular}

Commission-Helsinki Commission) and the contracting parties are Denmark, Estonia, Finland, Germany, Latvia, Lithuania, Poland, Russia, Sweden and the EU.

HELCOM works with a wide range of sectors and themes that have an influence on the environmental quality of the Baltic Sea and these include agriculture, fisheries, industrial and municipal releases, marine litter and noise pollution, marine protected areas, maritime spatial planning, monitoring and assessment, response to spills, species and biotopes and shipping [19]. This wideranging work has a potential impact on a variety of issues concerning health and well-being.

HELCOM adopted the Baltic Sea Action Plan (BSAP) in 2007 with the aim to restore the Baltic Sea to Good Environmental Status (GES) by 2021. As the current period is due to end soon, HELCOM are undergoing a review of their aims and objectives with a greater emphasis on economic and social benefits. This synthesis was conducted in conjunction with participatory input from members of the HELCOM GEAR group and therefore the information found will be of use to the stakeholders.

The relationships between the environmental interventions and the impacts on human health and well-being remains unclear with the information scattered across disciplines and inconsistent indices used to measure the impacts [25, 28]. This scattered information from multiple sources is inaccessible to policy and decisionmakers, as it requires interpretation to confirm the linkages between human health and well-being outcomes and the intentions of the interventions [25]. These linkages are not often simple relationships, therefore, there is a need to understand the trade-offs and synergies between different interventions in meeting specific health and well-being targets and be based on the best available evidence [25, 31].

The Baltic Sea ecosystems supply many unique benefits to society $[2,16,34]$. The benefits from the sea contribute to the health and well-being of individuals and communities through provisioning services such as food, medicines, fertilisers; regulatory services such as the regulation of harmful substances and clean water; and finally cultural services such as the traditional activities like ice-sea fishing or the spiritual/religious beliefs associated with the Baltic Sea maritime and coastal ecosystems. These services depend upon a healthy environment and the Baltic Sea countries have worked towards an integration of marine policies to ensure the health of the Baltic Sea ecosystems. Until recently, however, these policies have not taken into account the impact of the ecosystem services on human health and well-being, they have largely focussed on the impact of human activities on the environment [29].

This synthesis, therefore, aims to identify relationships and pathways between the exposure (ecosystem services) and the outcomes (human health and well-being) of the Baltic Sea domain. The theory of change flowchart (Fig. 1) will essentially provide a simplified framework showing the linkages that will be explored and where present, documented, in the evidence base.

The health synthesis will gather evidence from a variety of sources, both academic and grey literature that demonstrate an impact of an ecosystem service on health and well-being of people exposed to the Baltic Sea marine and coastal ecosystems through the effects of the Baltic Sea Ecosystem Services (BSES). These will then be presented to the key stakeholders and policymakers in an understandable format.

\section{Stakeholder engagement}

From the outset, we have taken a transdisciplinary approach, with plans to involve stakeholders at the different phases of the review process $[13,22,23]$. The aim is to gain insight into the policy relevance of emerging risks and benefits to public health from ecosystem services supplied by the Baltic Sea and how decision-makers could be supported in developing appropriate evidence-based policies. Five stakeholder interviews were conducted with the aim to define the review question, identify relevant topics and to validate the search criteria. Further workshops and outreach to additional stakeholders suggested by the initial interviewees will be conducted. Whilst endeavours have been made to integrate human health and well-being with ecosystem services into marine policies, interviews with key stakeholders in HELCOM and the HELCOM GEAR Group (Group on the Implementation of the Ecosystem Approach), revealed that the linkages were neither sufficiently strong nor well-known to inform policymaking. A synthesis is therefore required to provide information on what is known and highlight the knowledge gaps. An open dialogue with the stakeholders is enabled by sending updates of the review progress to the key stakeholders (e.g. HELCOM GEAR working group). 


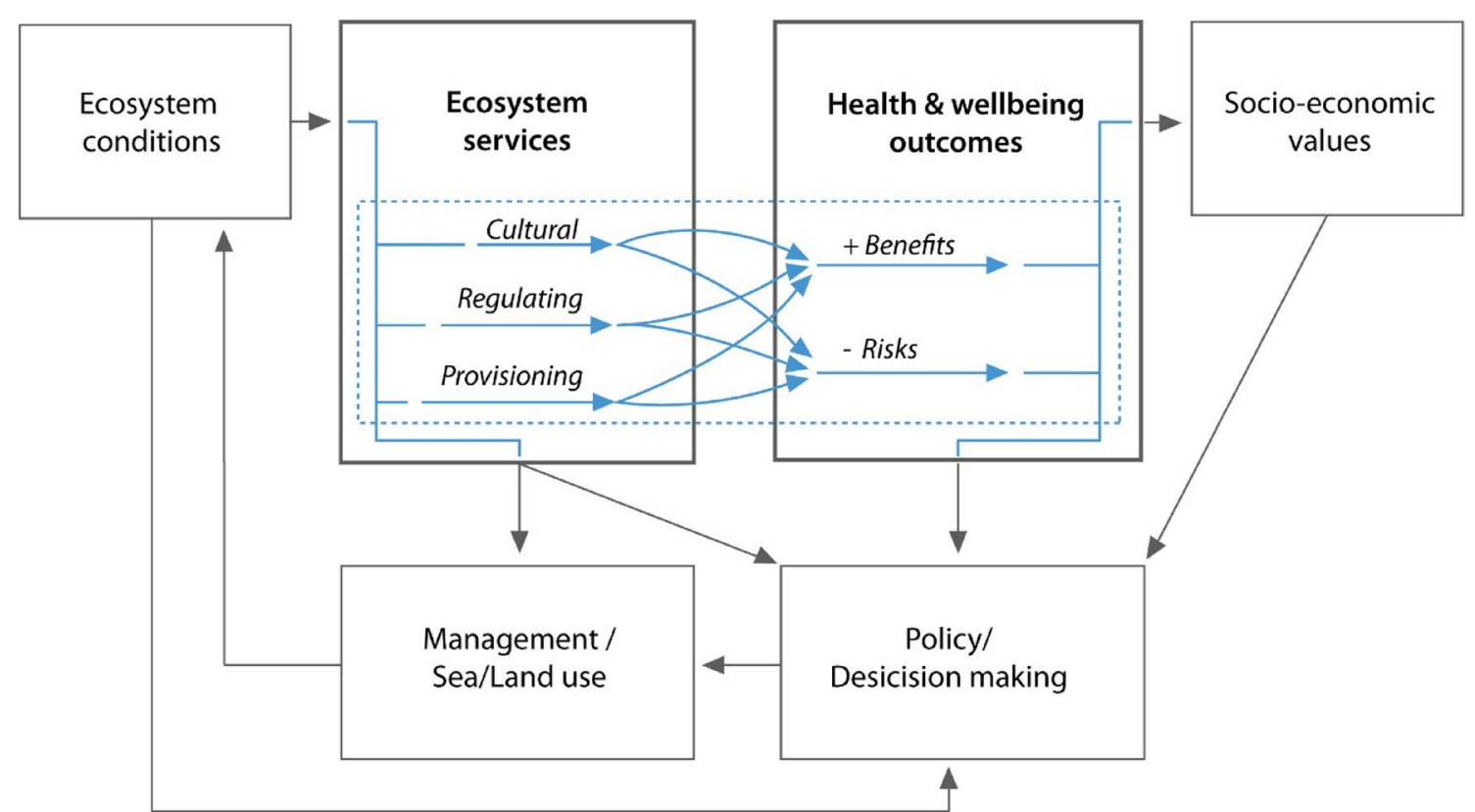

Fig. 1 A conceptual theory of change chart illustrating the health synthesis, i.e. a systematic mapping of the Baltic Sea ecosystem effects on human health and well-being (in bold), and showing the linkages to the larger socio-economic policies and ecosystem conditions framework

\section{Objective of the review \\ Objective}

This systematic map aims to bring together existing research evidence linking the health and well-being of coastal populations and those exposed to the ecosystem services in the Baltic Sea region. A systematic mapping review examining the linkages between all European marine environments and human health has been initiated by Cox et al. [9], but this does not focus on the Baltic Sea nor explicitly examines ecosystem services. Our search will therefore include information about studies linked to the following:

The outcome will consist of the health benefits and threats from the marine ecosystems evident from the systematic search of the studies. The map's geographical scope will be limited to the Baltic Sea, its sub-basins, and its coastal areas in accordance with the geographical scope defined by the funding call [6].

Primary question: What linkages have been researched between the Baltic Sea ecosystems and their services, and the positive and negative impacts to human health and well-being?

Systematic mapping has been developed to collate, describe and catalogue literature across multiple disciplines [20]. We will use a more open, emerging format of the primary question (i.e. PEO) because we will conduct a map (i.e. not a review) [4], p. 3.

Population: Health and well-being studies linked to the human populations within the marine and coastal environment of the Baltic Sea region.
Exposure: Exposure to the Baltic Sea ecosystems and their services.

Outcome measures: Aspects of human health and well-being.

\section{Methods}

Our focus is on Baltic Sea ecosystems and their services in relation to human health and well-being. An initial scoping exercise was carried out to examine the marine polices and reports related to the Baltic Sea ecosystem, such as the Marine Strategy Framework Directive and the work of HELCOM. These set the context for ecosystems present in the Baltic Sea and their governance. However, currently little mention is made of ecosystem services and the impacts on health and well-being, and its relevance to policymaking. The linkages therefore need to be made explicit. The map will, therefore, first categorise the ecosystem services according to the Common International Classification of Ecosystem Services (CICES) typology, which are relevant to the Baltic Sea ecosystems with impacts on human health and well-being $[15,17,18]$. The health and well-being categories will be broadly defined and adapted from McKinnon et al.'s domains and definitions. The mapping exercise will focus on the health and well-being of individuals, households or communities impacted by the ecosystem services within the Baltic Sea.

Throughout the process the evidence mapping will be guided by partners in the BONUS ROSEMARIE project, in consultation with stakeholders and the advisory board 
of the project. The systematic map follows the CEE guidelines [32] and ROSES protocol [14] (Additional file 1).

\section{Searches}

Through the searches we will aim to capture all of the available scientific evidence to answer the question. No restrictions considering the publication date of literature will be applied. Different sources of information will be searched to maximise the coverage of the results including:

- Electronic bibliographic databases;

- Website searches, including Government and relevant third sector websites;

- Backwards and forwards citation searching of included references, and using other relevant systematic maps and reviews.

\section{Search strategy}

We aim to capture all relevant scientific studies and relevant material from the grey-literature. For this, a scoping exercise was undertaken that included an initial review of the grey literature relevant to the Baltic Sea ecosystems at different levels (UN, EU, Baltic Sea Region, HELCOM see Additional file 2: Search strategy and, Additional file 3: Risks and benefits related to MSFD). This set the context for the article search strategy, highlighting the role that the relevant governance organisations played in managing the Baltic Sea ecosystem. Stakeholders and experts in ecosystem services were consulted to understand the needs of the organisations for evidence to incorporate into the search strategy and the ecosystem services relevant to the Baltic Sea. The CEE journal was also checked for related protocols, those determined as most relevant included McKinnon et al. [28] for health and well-being search terms and Liquete et al. [24] for ecosystem services search terms. In the event the database does not support a complex enquiry, the search string will be modified accordingly.

\section{Search string}

The search string is divided into the following parts

\begin{tabular}{l} 
Geographical keywords \\
\hline$\# 1$ "Aland sea" OR "Archipelago sea" OR "Arkona basin" OR"Baltic \\
proper" OR "Baltic sea" OR "Bay of Mecklenburg" OR "Belt sea" \\
OR"Bornholm basin" OR "Bothnian bay" OR "Bothnian sea" \\
OR "Gdansk basin" OR"Gdansk bay" OR "Gdansk gulf" OR \\
"Gotland basin" OR "Great Belt" OR "Gulf of Bothnia" OR "Gulf \\
of Finland" OR "Gulf of Riga" OR Kattegat OR "Kiel bay" OR \\
Kvarken OR"Mecklenburg bay" OR"Vistula bayî OR "Vistula \\
lagoon"
\end{tabular}

\#2 Baltic OR Danish OR Denmark OR Estonia* OR Finland OR Finnish OR German* OR Kaliningrad OR Latvia* OR Lithuania* OR Neva OR Poland OR Polish OR "Saint-Petersburg" OR "St. Petersburg" OR Sweden OR Swedish

\#3 archipelago OR beach* OR "blue space" OR coast* OR estuary OR harbour OR island* OR jetty OR lagoon OR marine OR port OR quay OR saltmarsh OR seaboard* OR seacoast* OR "sea-coast*" OR seafront* OR seascape* OR seashore* OR seaside OR shore* OR waterfront*

Human qualifier keywords

\#4 children OR collaborative OR fisher* OR household* OR human* OR infan* OR "local communit*" OR matern* OR people OR person* OR pregnan* OR societ*

Ecosystem keywords

\#5 aesthet* OR "air quality" OR aquacultur* OR art OR assimilat* OR attenuat* OR biodiversity OR biofilt* OR "biogeochemical services" OR biomass OR bioremediation OR biosecurity OR birdwatching OR buffer* OR catch OR "coastal protection" OR cognitive OR conservat* OR control OR cultur* OR denitrificat* OR deposit* OR detoxific ${ }^{*}$ OR disease OR diversity OR "ecosystem services" OR ecosystem* OR ecotouris* OR filter* OR fish* OR habitat OR harvest* OR hunting OR identity OR improve* OR informat* OR inspirat* OR leisure OR minerali* OR mitigat* OR"non-consumptive use" OR nursery OR "nutrient cycl*" OR "nutrient recycl*"OR pest OR photosynthesis OR pollinat* OR prevention OR product* OR provision* OR purificat* OR "quality maint ${ }^{*}$ "OR "raw materials" OR recreat* OR reduct* OR refug* OR regenerat* OR regulat* OR remov* $O R$ research $O R$ resources $O R$ retent* OR sequestrat* $O R$ stabilization OR storage OR touris* OR treatment OR uptake OR "water quality" OR wildlife

Human well-being and health keywords

\#6 accountability OR amenit* OR antibiotic* OR assets OR attitude* OR "basic needs" OR beliefs OR capital* OR "clean water" OR conflict* OR connectedness OR damage* OR "decision making" OR destruction* OR detriment* OR distress* OR drown* OR "economic living standards" OR ecotoxic* OR educat* OR employment OR "employment opportunities" OR empower* OR "endocrine disruptor*" OR equity OR eutrophic* OR exposure* OR fatalit* OR fibre OR food OR "freedom of action" OR "freedom of choice" OR fuel OR governance OR happiness OR harm* OR hazard OR health OR heritage OR "human rights" OR identity OR illness* OR income OR infection* OR infrastructure OR injur* OR interaction* OR intoxicat* OR job* OR justice OR knowledge OR "life expectancy" OR livelihood* OR longevity OR loss* OR "material living standards" OR microplastic* OR mortal* OR neurotoxin* OR nutrition* OR participation OR payments OR perception* OR pharmaceutical* OR "physical health" OR plastic or plastics OR poison* OR pollut* OR poverty OR "quality of life" OR relationship* OR resilience* OR safety OR satisfact* OR savings OR security OR "sense of home" OR skill* $O R$ "social relations" OR "societal values" OR "spiritual values" OR spirituality OR stress* ORTEK OR toxic* OR toxin* OR "traditional knowledge" OR "traditional values" OR transparency OR trust OR utilit* OR values OR wealth OR "well being" OR wellbeing OR well-being OR vulnerability OR "basic needs" OR "mental health" OR "physical health"

Final combination of the search groups

\#7 (\#1 OR (\#2 AND \#3)) AND \#4 AND \#5 AND \#6

Test searches in the Web of Science (Core collection) revealed a problem with Web of Science Keywords plus function (an artificial intelligence supported search), this lead to many irrelevant articles. Due to 
pragmatic reasons of time and resource constraints, title and abstract searches only were conducted, not topic searches, to obtain the articles for the mapping exercise. This removed the issue found with the Keywords plus function.

Languages-Bibliographic: English

Languages-grey literature: The national MSFD (Marine Strategy Framework Directive) reports as well as the HELCOM HOLAS (Holistic Assessment of the Ecosystem Health Of the Baltic Sea) reports I and II will be screened in English, Swedish, Finnish, Estonian, and German (representing the languages spoken in the BONUS ROSEMARIE project consortium).

\section{Bibliographic databases}

Searches will be carried out in English using the following databases and platforms for relevant literature.

- Web of Science (Core Collection + Medline): https:// www.webofknowledge.com

- Scopus: https://www.scopus.com/

- CAB Abstracts: https://www.cabi.org/

- PubMed https://pubmed.ncbi.nlm.nih.gov/

- EMBASE: https://www.elsevier.com/solutions/embas e-biomedical-research

- Libris: http://libris.kb.se/

- Melinda: https://melinda.kansalliskirjasto.fi/

- Ester: https://www.ester.ee/search S1

- DNL-online: http://www.dnl-online.de/

- GEO-LEO-portal: https://geo-leo.de/

- German National Library: https://www.dnb.de/EN/ Kataloge/kataloge_node.html

- Central Geographical Library (GZB): https://www. ifl-leipzig.de/en/library.html

In the case that the database does not support complex strings, they will be amended as necessary

\section{Web-based search engines}

Focussed internet searches will also be carried out in order to capture relevant grey literature such as government reports, organisation reports, consultant reports, theses and so on. In accordance with Haddaway et al. [14], the first 300 results will be included for screening.

- Bielefeld Academic Search Engine (BASE): https:// www.base-search.net/

- CORE: https://core.ac.uk/

- 1FINDR: https://1findr.1science.com/home

- Directory of Open Access Journals:
- Google: https://www.google.com/

- Google Scholar: https://scholar.google.com/

\section{Organisational websites}

Manual screening of Baltic Sea ecosystems related organisations will be carried out. The first 20 results will be taken and screened for relevance. The results will then be combined with the other search results. These searches will also be carried out in English language, as well as Swedish, Finnish, Estonian and German where applicable.

- Baltic Environmental Forum: http://bef.ee/en/truki sed/

- Coalition Baltic Sea: https://ccb.se/

- Estonian Ministry of Environment https://www.envir .ee/en

- Finnish Environment Library Collections: http://kirja sto.ymparisto.fi/syke/en/search_yha.htm

- German Environment Agency (Umweltbundesamt): https://www.umweltbundesamt.de/en

- HELCOM: http://www.helcom.fi/

- Institutional Repository of Finnish ministries (Valto): https://julkaisut.valtioneuvosto.fi/

- Swedish Ministry of the Environment: https://www. government.se/government-of-sweden/ministry-ofthe-environment/

\section{Estimating the comprehensiveness of the search}

Seven publications of known relevance to health and well-being in the Baltic Sea ecosystems were chosen as a benchmark list (see Additional file 4) to test the relevance of the search procedure. The articles for the benchmark list were selected from various reports issued by HELCOM, to cover the various aspects of health and wellbeing and related to Baltic Sea ecosystem services, as considered in this synthesis and in consultation with relevant experts. In establishing the benchmark list, we have worked in consultation with our advisory board, and our initial scoping review of the policy documents related to the Baltic Sea (e.g. Baltic Sea status report by HELCOM). Additionally, we will screen the reference lists for all relevant existing review articles to detect applicable empirical research for our synthesis.

\section{Article screening and study eligibility criteria Screening strategy}

Studies will be screened according to predefined screening criteria at title, abstract and keyword level. Full text screening will be performed using pre-defined categories (see Additional file 5) derived from health and well-being 
keywords [7-9, 28] and ecosystem services keywords [24]. However we propose to map all the literature on the health and well-being impacts from the Baltic Sea ecosystems and their services without narrowing the scope of the study based on study design [8].

\section{Demonstrating procedural independence}

In cases where studies occur in our sample which are co-authored by any of the synthesis team members, the respective team member will not screen, code or be involved in other steps of the systematic mapping process for that study. We will seek support from other project team members in such cases.

\section{Consistency checking}

A consistency check will be undertaken at the abstract/ title stage on a random selection of articles from a preliminary literature search. Fifty articles will be assessed by three screeners using pre-defined inclusion criteria. Any potential disagreements will be solved via discussion (if necessary, with the whole synthesis team) and inclusion criteria will be amended accordingly. The consistency check will be carried out until a kappa result of 0.7 or above is achieved [27]. After the initial screening has been undertaken and there is consistency two screeners continue the check at title and abstract level with a further random subset of materials (5\% of the total records) being screened by both to guarantee that decisions regarding inclusion/exclusion criteria are applied consistently.

Full text screening consistency check will be carried out on $5 \%$ of the articles that fulfil the inclusion criteria and can be accessed, with two screeners working independently to produce a final set of articles for the data extraction process.

A double data coding strategy by two coders will be then be used for the data extraction process, with the research team meeting regularly to discuss any ambiguous or unresolved articles [28]. The online systematic mapping tool CADIMA [37] will be used and a 5\% consistency check will be applied to the data coding process.

\section{Inclusion criteria \\ Geographical}

Only evidence from Baltic Sea marine and coastal ecosystems will be included.

\section{Population}

The study addresses health and well-being factors of human populations including individuals, households or communities within the coastal or marine ecosystem of the Baltic Sea countries identified in the literature review and during the consultation process.

\section{Exposure}

The study involves the impacts of exposure to Baltic Sea ecosystem services (service categories according to CICES typology), which has a link to defined human health and well-being factors. See Additional file 3: Risks and benefits related to MSFD.

\section{Outcome}

The study assesses the positive or negative effects of ecosystem services on multi-dimensional health and well-being status of the human population.

\section{Study validity assessment}

According to the CEE guidelines, study validity assessments are not necessary for systematic maps [32]. Additionally, we will not attempt any critical appraisal of individual studies, nor will we attempt to quantify or validate the health and well-being impacts. The aim is to begin to examine how the linkages between the ecosystem services supplied by the Baltic Sea and health and well-being outcomes have been made in the literature and synthesise them. Moreover, the intention is to stimulate the debate and encourage the scientific and marine planning communities to think widely about the policy implications on health and well-being and provide them with the available evidence as a summary. It is anticipated that this will enable policymakers to strengthen their efforts in working towards good environmental status as directed in the European Union's Marine Strategy Framework Directive through the justification of health and well-being impacts. It will also increase awareness of the trade-offs and benefits of reaching good environmental status on health and well-being.

\section{Data coding strategy}

A minimum of two screeners will extract and code relevant meta-data characteristics (e.g. country, study location, methods used and bibliographic information) as well as data on specific variables which are of topical interest for this synthesis (e.g. health and well-being outcomes, factors contributing to these outcomes, including policy measures as reported in the studies. The coding strategy (Additional file 5) is based on McKinnon et al's [28] domains and definitions, Good Environmental Status indicators and the relevant policies linked to our study, such as BSAP (Baltic Sea Action Plan). Coding will be applied to all studies that passed the initial screening levels and are available as full texts.

Variables of interest include the following blocks (details in Coding strategy, Additional file 5): 
- Bibliographic information (e.g. source, title).

- Study description (e.g. language, publication type) and location (e.g. case study country).

- Research methods, incl. outcome measurement methods.

- Exposure description (e.g. ecosystem services' classification concepts, service groups).

- Human health and wellbeing outcomes (e.g. living standards, health aspects, culture).

- Policy relevance (e.g. BSAP goals, MSFD descriptors).

\section{Study mapping and presentation}

For the mapping, we plan to combine techniques from two approaches: framework synthesis [30] and critical interpretive synthesis [10]. Framework synthesis and critical interpretive synthesis were chosen because both can handle qualitative, quantitative and mixed data. Framework synthesis departs from a more realist epistemology, i.e. considers some pre-defined aspects (e.g. a defined research question, plus a pre-defined general framework) and has a more aggregative approach to data analysis, while critical interpretive synthesis relies on a more open and constructionist perspective. Based on the aggregated information from our article search we will develop the framework derived from our initial review of the background literature and our theory of change: i.e. (a) the various types of health and wellbeing outcomes (b) related to the Baltic Sea and its ecosystem services, and (c) with the policies (Marine Strategy Framework Directive 2008 and Baltic Sea Action plan 2007) affecting the provision of the services at the background (Fig. 1). Via this process, we aim to create a revised framework of the health and wellbeing outcome types, which specifically focuses on the Baltic Sea-as this has not been systematically synthesized yet-and linked to ecosystem services to inform Baltic Sea policies.

We will also aim to produce heat maps which compare variables pairwise to indicate the extent of evidence available.

\section{Supplementary information}

Supplementary information accompanies this paper at https://doi. org/10.1186/s13750-020-00189-6.

Additional file 1. ROSES form.

Additional file 2. Search strategy.

Additional file 3. Risks and benefits related to MSFD.

Additional file 4. Benchmark articles.

Additional file 5. Coding strategy.

\section{Acknowledgements}

The authors would like to thank all colleagues in the BONUS ROSEMARIE project. We would also like to thank the four representatives from the HELCOM group and the marine protection specialist that we interviewed for their input into the protocol and the coming systematic map. We appreciate Gloria Niin for her substantial contribution in preparation of the figure. Finally, we would like to thank our advisory board, Rebecca Rees, Mathew White, and Nicola Beaumont, for their valuable feedback and advice.

\section{Authors' contributions}

The protocol was drafted by JS, MS and MK with expert contributions from SV, VL, KK, HK and SO. The systematic map focus and development of the research question was undertaken by JS, MS and MK. JS, SR, MS and VL collaborated on the search strategy. All authors read and approved the final manuscript.

\section{Funding}

This study was supported through BONUS ROSEMARIE. The project received funding from BONUS (Art. 185), funded jointly by the EU and the Swedish Research Council FORMAS and the Estonian Research Council.

\section{Availability of data and materials}

Not applicable.

Ethics approval and consent to participate

Not applicable.

Consent for publications

Not applicable.

\section{Competing interests}

The authors declare that they have no competing interests.

\section{Author details}

${ }^{1}$ Estonian University of Life Sciences, Kreutzwaldi 1, 51006 Tartu, Estonia.

2 Finnish Environment Institute, Latokartanonkaari 11, 00790 Helsinki, Finland.

${ }^{3}$ Institute of Physical Geography and Landscape Ecology, Gottfried Wilhelm

Leibniz University Hanover, Schneiderberg 50, 30167 Hanover, Germany.

Received: 19 June 2019 Accepted: 19 March 2020

Published online: 31 March 2020

\section{References}

1. Aerts R, Honnay O, Van Nieuwenhuyse A. Biodiversity and human health: mechanisms and evidence of the positive health effects of diversity in nature and green spaces. Br Med Bull. 2018;127(1):5-22.

2. Ahtiainen $\mathrm{H}$, Öhman MC. Ecosystem services in the Baltic Sea. Copenhagen: Nordic Council of Ministers; 2014.

3. Ban NC, Gurney GG, Marshall NA, Whitney CK, Mills M, Gelcich S, Bennett NJ, Meehan MC, Butler C, Ban S, Tran TC, Cox ME, Breslow SJ. Well-being outcomes of marine protected areas. Nat Sustain. 2019;2(6):524-32.

4. Berger-Tal O, Greggor AL, Macura B, Adams CA, Blumenthal A, Bouskila A, Candolin U, Doran C, Fernández-Juricic E, Gotanda KM, Price C, Putman BJ, Segoli M, Snijders L, Wong BBM, Blumstein DT. Systematic reviews and maps as tools for applying behavioral ecology to management and policy. Behav Ecol. 2019;30(1):1-8.

5. Blythe J, Armitage D, Alonso G, Campbell D, Dias ACE, Epstein G, Marschke $M$, Nayak P. Frontiers in coastal well-being and ecosystem services research: a systematic review. Ocean Coast Manag. 2019. https://doi. org/10.1016/j.ocecoaman.2019.105028.

6. BONUS. BONUS call 2017: synthesis. 2017. https://www.bonusportal.org/ programme/competitive_calls/bonus_call_2017_synthesis. Accessed 4 Oct 2019

7. Bottrill M, Cheng S, Garside R, Wongbusarakum S, Roe D, Holland MB, Edmond J, Turner WR. What are the impacts of nature conservation interventions on human well-being: a systematic map protocol. Environ Evid. 2014;3(1):16.

8. Cheng SH, MacLeod K, Ahlroth S, Onder S, Perge E, Shyamsundar P, Rana P, Garside R, Kristjanson P, McKinnon MC, Miller DC. A systematic map of 
evidence on the contribution of forests to poverty alleviation. Environ Evid. 2019;8(1):1-22.

9. Cox DTC, Bethel A, Garside R. 2019. What linkages have been researched between the marine environment and human health? A systematic map protocol. CADIMA.

10. Dixon-Woods M, Cavers D, Agarwal S, Annandale E, Arthur A, Harvey J, Hsu R, Katbamna S, Olsen R, Smith L, Riley R, Sutton AJ. Conducting a critical interpretive synthesis of the literature on access to healthcare by vulnerable groups. BMC Med Res Methodol. 2006;6:1-13.

11. Eurostat. Eurostat population data. Eurostat data browser. 2019. https ://ec.europa.eu/eurostat/databrowser/view/tps00001/default/table ?lang=en. Accessed 11 Dec 2019.

12. Fleming $L E$, Maycock $B$, White MP, Depledge MH. Fostering human health through ocean sustainability in the 21st century. People Nat. 2019. https ://doi.org/10.1002/pan3.10038.

13. Haddaway NR, Kohl C, Da Silva NR, Schiemann J, Spök A, Stewart R, Sweet JB, Wilhelm R. A framework for stakeholder engagement during systematic reviews and maps in environmental management. Environ Evid. 2017;6(1):11.

14. Haddaway NR, Macura B, Whaley P, Pullin AS. ROSES reporting standards for systematic evidence syntheses: pro forma, flow-diagram and descriptive summary of the plan and conduct of environmental systematic reviews and systematic maps. Environ Evid. 2018;7(1):4-11.

15. Haines-Young R, Potschin M. Common international classification of ecosystem services (CICES) V5. 1. Guidance on the application of the revised structure. 2018.

16. Hasler B, Ahtiainen H, Hasselström L, Heiskanen A-S, Soutukorva Å, Martinsen L. Marine ecosystem services: marine ecosystem services in nordic marine waters and the Baltic Sea—possibilities for valuation. TemaNord. 2016;501:1-155.

17. HELCOM. EConomic and social analyses in the Baltic Sea region-HELCOM thematic assessment 2011-2016. 2018.

18. HELCOM. State of the Baltic Sea-second HELCOM holistic assessment 2011-2016. 2018

19. HELCOM. Baltic marine environment protection commission. 2019.

20. James KL, Randall NP, Haddaway NR. A methodology for systematic mapping in environmental sciences. Environ Evid. 2016;5(1):1-13.

21. Kensa VM. Biodiversity and health. Asian J Microbiol Biotechnol Environ Exp Sci. 2012;14(4):527-8.

22. Langer L, Erasmus Y, Tannous N, Stewart R. How stakeholder engagement has led us to reconsider definitions of rigour in systematic reviews. Environ Evid. 2017;6(1):20

23. Larsen RK, Nilsson AE. Knowledge production and environmental conflict: managing systematic reviews and maps for constructive outcomes. Environ Evid. 2017;6(1):17.

24. Liquete C, Piroddi C, Drakou EG, Gurney L, Katsanevakis S, Charef A, Egoh B. Current status and future prospects for the assessment of marine and coastal ecosystem services: a systematic review. PLOS ONE. 2013;8(7):e67737.

25. Lovell R, Wheeler BW, Higgins SL, Irvine KN, Depledge MH. A systematic review of the health and well-being benefits of biodiverse environments. J Toxicol Environ Health B Crit Rev. 2014;17(1):1-20.
26. Martin CL, Momtaz S, Gaston T, Moltschaniwskyj NA. A systematic quantitative review of coastal and marine cultural ecosystem services: current status and future research. Mar Policy. 2016;74:25-32.

27. McIntosh EJ, Chapman S, Kearney SG, Williams B, Althor G, Thorn JPR, Pressey RL, McKinnon MC, Grenyer R. Absence of evidence for the conservation outcomes of systematic conservation planning around the globe: a systematic map. Environ Evid. 2018;7(1):1-23.

28. Mckinnon MC, Cheng SH, Dupre S, Edmond J, Garside R, Glew L, Holland MB, Levine E, Masuda YJ, Miller DC, Oliveira I. What are the effects of nature conservation on human well-being ? A systematic map of empirical evidence from developing countries. Environ Evid. 2016;5:1-25.

29. Moore MN, Depledge MH, Fleming L, Hess P, Lees D, Leonard P, Madsen L, Owen R, Pirlet H, Seys J, Vasconcelos V, Viarengo A. Oceans and human health $(\mathrm{OHH})$ : a European perspective from the marine board of the European science foundation (Marine Board-ESF). Microb Ecol. 2013;65(4):889-900.

30. Oliver SR, Rees RW, Clarke-Jones L, Milne R, Oakley AR, Gabbay J, Stein K, Buchanan P, Gyte G. A multidimensional conceptual framework for analysing public involvement in health services research. Health Expect. 2008;11(1):72-84.

31. Pullin AS, Bangpan M, Dalrymple S, Dickson K, Haddaway NR, Healey JR, Hauari H, Hockley N, Jones JPG, Knight T, Vigurs C, Oliver S. Human wellbeing impacts of terrestrial protected areas. Environ Evid. 2013;2(1):19.

32. Pullin AS, Frampton GK, Livoreil B, Petrokofsky G. Collaboration for environmental evidence. 2018. Guidelines and standards for evidence synthesis in environmental management. version 5.0. Collaboration for Environmental Evidence. 2018.

33. Rasheed AR. Marine protected areas and human well-being - a systematic review and recommendations. Ecosyst Serv. 2020;41:101048.

34. Sagebiel J, Schwartz C, Rhozyel M, Rajmis S, Hirschfeld J. Economic valuation of baltic marine ecosystem services: blind spots and limited consistency. ICES J Mar Sci. 2016;73(4):991-1003.

35. Sandifer PA, Sutton-Grier AE, Ward BP. Exploring connections among nature, biodiversity, ecosystem services, and human health and wellbeing: opportunities to enhance health and biodiversity conservation. Ecosyst Serv. 2015;12:1-15.

36. Summers JK, Smith LM, Case JL, Linthurst RA. A review of the elements of human well-being with an emphasis on the contribution of ecosystem services. Ambio. 2012;41(4):327-40.

37. Unger S, Kluth R, Schreiber T, Kecke S. CADIMA: a web tool facilitating the conduct and assuring for the documentation of systematic reviews, systematic maps and further literature reviews. 2019.

\section{Publisher's Note}

Springer Nature remains neutral with regard to jurisdictional claims in published maps and institutional affiliations.

Ready to submit your research? Choose BMC and benefit from:

- fast, convenient online submission

- thorough peer review by experienced researchers in your field

- rapid publication on acceptance

- support for research data, including large and complex data types

- gold Open Access which fosters wider collaboration and increased citations

- maximum visibility for your research: over $100 \mathrm{M}$ website views per year

At BMC, research is always in progress.

Learn more biomedcentral.com/submissions 